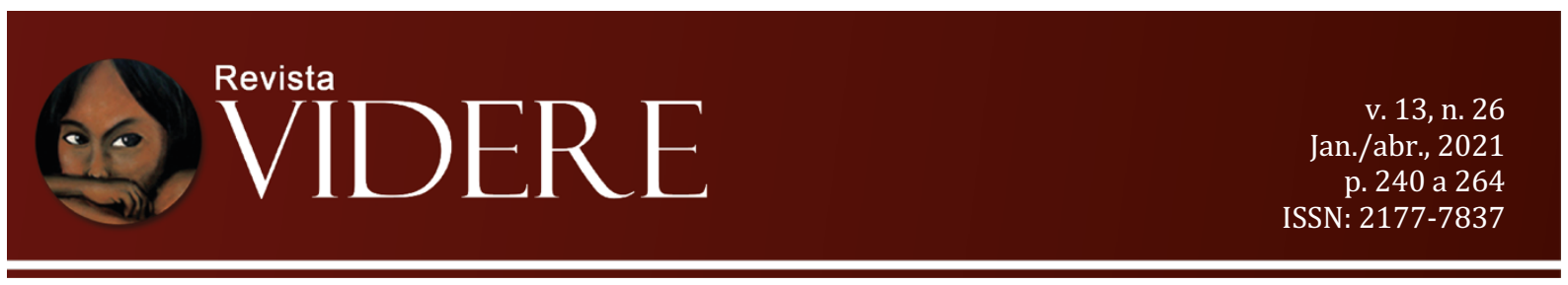

\title{
É POSSÍVEL ECOLOGIZAR OS DIREITOS HUMANOS DESDE O FEMINISMO COMUNITÁRIO?
}

\author{
IS IT POSSIBLE TO ECOLOGIZE HUMAN RIGHTS SINCE COMMUNITY FEMINISM?
¿ES POSIBLE ECOLOGIZAR LOS DERECHOS HUMANOS DESDE EL FEMINISMO
COMUNITARIO?

\begin{abstract}
Flávia Hardt Schreiner
Graduada em Ciências Jurídicas e Sociais pela Universidade Federal de Santa Maria (UFSM). Mestra em Estudos Interdisciplinares sobre Gênero, Mulheres e Feminismo pela Universidade Federal da Bahia (UFBA). Advogada e pesquisadora feminista. flavia.hardt@gmail.com CV Lattes: http://lattes.cnpq.br/5538666121663024. https://orcid.org/0000-0002-3593-5354
\end{abstract}

Lina Maria Brandao de Aras Graduada em Licenciatura e Bacharelado em História pela Universidade Federal da Bahia (1983), mestrado em História pela Universidade Federal de Pernambuco (1989), doutorado em História Social pela Universidade de São Paulo (1995) e pós-doutorado na Universidade Federal de Pernambuco (2009-2010). É Professora Titular do Departamento de História, da Universidade Federal da Bahia. http://orcid.org/0000-0002-0432-7508

RESUMO: Este artigo tem por objetivo explorar uma teoria jurídica em emancipação e propõe uma viragem ecocêntrica e decolonial dos Direitos Humanos. Analisam-se as práticas e as teorias dos feminismos comunitários latino-americanos para evidenciar uma contranarrativa, demonstrando-se que as mulheres comunitárias propõem novos critérios epistemológicos capazes de promover a ecologização desses direitos e, também, a descolonização da ciência jurídica como um todo. O estudo, por fim, evidencia um horizonte dinâmico para os Direitos Humanos, pois essas epistemologias possibilitam condições concretas de mobilização e zelo para com os direitos fundamentais e com o meio ambiente equilibrado, estruturadas em uma cosmovisão integrativa que promove o valor intrínseco da natureza. Como alternativa metodológica, optou-se pela revisão bibliográfica narrativa, de caráter descritivo e propositivo e abordagem hipotética-dedutiva, elegendo como marcos teóricos as teorias críticas do direito, as teorias decoloniais e as teorias feministas.

PALAVRAS-CHAVE: Feminismo Comunitário. América Latina. Direitos Humanos. Ecologização do Direito.

ABSTRACT: This article aims to explore a legal theory in emancipation and an ecocentric and decolonial shift in Human Rights. The practices and theories of Latin American community feminisms are analyzed to show an alternative narrative, demonstrating that community women 
propose new epistemological criteria capable of promoting an ecologization of these rights and a decolonization of legal science as a whole. Finally, the study reveals a dynamic horizon for Human Rights, as these epistemologies enable concrete conditions for mobilization and care for fundamental rights and a balanced environment, structured in an integrative worldview that promotes the intrinsic value of nature. As methodological, this work is based on a bibliographic narrative review, of a descriptive and propositive nature and hypothetical-deductive approach, choosing as theoretical alternatives the critical theories of law, decolonial theories and feminist theories.

KEYWORDS: Community Feminism. Latin America. Human Rights. Greening of Law.

RESUMEN: Este artículo tiene como objetivo explorar una teoría jurídica en emancipación y propone un cambio ecocéntrico y descolonial en los Derechos Humanos. Se analizan las prácticas y teorías de los feminismos comunitarios latinoamericanos para demostrar una contranarrativa, demostrando que las mujeres comunitarias proponen nuevos criterios epistemológicos capaces de promover el enverdecimiento de estos derechos y también la descolonización de la ciencia jurídica en su conjunto. Finalmente, el estudio muestra un horizonte dinámico para los Derechos Humanos, ya que estas epistemologías posibilitan condiciones concretas para la movilización y afán por los derechos fundamentales y un entorno equilibrado, estructurado en una cosmovisión integradora que promueve el valor intrínseco de la naturaleza. Como alternativa metodológica, se optó por una revisión bibliográfica narrativa, de carácter descriptivo y propositivo y enfoque hipotético-deductivo, eligiendo como marcos teóricos teorías críticas del derecho, teorías decoloniales y teorías feministas.

PALABRAS ClAVE: Feminismo comunitario. América Latina. Derechos Humanos. Ecologización de la ley.

\section{INTRODUÇÃO}

A esfera da reprodução social da vida revela todas as mazelas originais do modo de produção capitalista. Nesse sentido, mais recentemente a crise ecológica tem sido associada à crise da reprodução social, para denunciar a exploração da natureza por uma economia financeirizada, a expropriação dos territórios e dos corpos humanos como força de trabalho produtiva, bem como a exploração laboral particular de certos grupos, como as mulheres (PÉREZ, 2014).

A economia é feita pelas pessoas e só existe com elas. Deveria ser, portanto, um modo de organização marcada pela interdependência humana e do meio natural (que garante a sobrevivência), sendo este um dos eixos do pensamento proposto pelas feministas comunitárias. Entretanto, a relação entre a economia e a vida na contemporaneidade é um verdadeiro dilema, conforme foi revelado pela atual pandemia do coronavírus.

A atual crise sanitária desencadeada pela pandemia do Coronavírus desmascarou a fragilidade, e em alguns casos, a ausência, de políticas voltadas à manutenção da vida, a qual se relaciona à própria proteção dos 
Direitos Humanos e à preservação meio ambiente. Este contexto abre um espaço para a discussão e o diálogo sobre novas (e antigas) formas de enfrentamento ao atual sistema econômico vigente.

Todo problema ambiental esboça uma questão socioambiental complexa que quase sempre nos desafia ao exercício da interdisciplinaridade. A reivindicação das lutas ambientais vinculadas à luta feminista comunitária aposta nas relações justas entre mulheres e homens, bem como na justiça socioambiental de maneira interligada. Por este motivo, as diversas posições feministas constituem ferramenta indispensável para entender as relações sociais nesses contextos específicos, bem como para analisar as formas de opressão que se geram na dinâmica global-local.

Segundo Federici (2020), as mulheres latino-americanas desempenham um papel central nas lutas ecológicas por serem as mais afetadas pela desapropriação, pela degradação ambiental e por serem responsáveis pela reprodução de suas famílias. Investigar esse contexto na defesa do meio ambiente e do território é uma forma de tornar visível as possibilidades de articulação das lutas feministas, indígenas, ambientalistas e de outros grupos sociais.

As relações de poder na sociedade consideram diversos marcadores sociais como categorias de análise, os quais significam relações de opressão e os capitais sociais em disputa na contemporaneidade. Assim, uma virada ecológica nas ciências jurídicas demanda uma visão holística, em que deve existir um todo maior que suas partes, integrativa e interdisciplinar, que permeie os campos de uma hermenêutica jurídica comprometida com os Direitos Humanos.

Por este motivo, a ecologização dos direitos propõe não desvincular considerações da ordem ambiental na apuracão de violações aos Direitos Humanos, e, além disso, na própria interpretação e teoria desses direitos. Trata-se de uma aposta hermenêutica expansiva do binômio humano-natureza no direito a partir da sabedoria comunitária feminista.

Apresentam-se neste trabalho contrapontos ao simples objetivismo empírico, pautando por delimitar o lugar ou os lugares em que se faz ciência. É imprescindível responder desde uma postura não cartesiana e não positivista: de onde falo, de onde me sustento? De modo geral, este trabalho está pautado em uma revisão bibliográfica narrativa, de caráter descritivo e propositivo, elegendo-se, como marcos teóricos, as teorias críticas do direito, as teorias decoloniais e as teorias feministas.

Como método de abordagem, optou-se pelo hipotético-dedutivo que parte de um problema que anseia ao menos uma solução provisória, passando-se à crítica de tal solução, com objetivo de eliminação dos 
equívocos e de novos problemas (LAKATOS; MARCONI, 1993, p. 95). Neste trabalho procura-se responder à pergunta: de que forma a teoria e a práxis feminista comunitária latinoamericana propõe novos critérios epistemológicos capazes de promover a ecologização dos Direitos Humanos?

A hipótese é de que esse questionamento é respondido através de uma cosmovisão integrativa que promove o valor intrínseco da natureza e dos seres que com que ela se relacionam. Diferente do método dedutivo de confirmar as hipóteses a qualquer custo, este método procura evidências empíricas que possam derrubar ou dar mais consistência à hipótese (LAKATOS; MARCONI, 1993, p. 95-96). Tal método pode ser aplicado de forma satisfatória, já que não se pretende a confirmação, pura e simplesmente da necessidade de um novo paradigma, mas sim de analisar grande parte das premissas envolvidas diante a realidade do século XXI e avançar rumo a novas propostas expansivas para a Teoria dos Direitos Humanos.

Como método de procedimento, optou-se pelo Monográfico, que visa examinar o objeto da pesquisa a partir de todos os fatores de influência (ou grande parte deles) (LAKATOS; MARCONI, 2003, p. 108). Assim, é possível estudar a totalidade do fenômeno, e, partindo de sua unidade, descobrir se as características do feminismo comunitário poderão ser refletidas na Teoria dos Direitos Humanos a fim de "ecologizá-lo", ou seja, de interpretá-lo sistemicamente com a preservação ambiental, concretizando-se o princípio da dignidade da pessoa humana de forma integral no contexto da América Latina.

No primeiro capítulo, tece-se um breve ensaio do paradigma tradicional dos Direitos Humanos e pugna-se pela reformulação do "humano" nesses direitos. Na segunda parte do artigo, os feminismos andinos e comunitários são descritos e localizados na Abya Yala. Na terceira parte do trabalho, a proposta é de relocalizar as ciências jurídicas e os Direitos Humanos a partir das mulheres comunitárias localizadas no Sul Global rumo à ecologização desses direitos.

A linguagem a ser utilizada constitui em uma escolha epistemológica que deve refletir os objetivos propostos. O pensamento crítico não pode ser fragmentado a fim de caber nesta ou naquela disciplina, neste ou naquele "ego teórico". Torna-se impossível atender a uma dinâmica complexa das relações sociais e jurídicas com um viés único estéril que elide a pluralidade dos saberes. Assim, o olhar deste trabalho parte de diversas disciplinas, interconexões e origens de cunho qualitativo. 


\section{BREVE ENSAIO PARA A REFORMULAÇÃO DO "HUMANO" DOS DIREITOS HUMANOS}

A historicidade ocidental encobre as experiências de lutas anticoloniais por Direitos Humanos e, em especial, difunde uma concepção histórica parcial, elevando-a ao nível universal. Foi no "século das luzes" que surgiu a raiz do Estado Democrático de Direito como conhecemos hoje. (BRAGATO, 2014)

Várias doutrinas desse período resultaram em um processo que formou a base da filosofia e da prática política liberal da modernidade e que forjou na ideia de democracia ocidental atual o trio dos valores "revolucionários" burgueses de liberdade, igualdade e fraternidade (PETIT, 1994). Essa "origem" viciada do Estado de Direito dialoga com os elementos históricos-sociais presentes nas teorias contratualistas (as quais eligem o que doutrinariamente se entende como Direito Moderno).

O contrato original também era corporificado e localizado em uma ordem social patriarcal em que a diferença sexual era também política: o contrato era social-sexual e legitimava a sujeição/dominação das mulheres, as quais eram meros objetos desse contrato (PATEMAN, 1993). O caráter masculino do contrato original, ou seja, um contrato entre homens, cujo objeto são as mulheres, delineou a diferença sexual expressada no corpo e a converteu em diferença política ${ }^{1}$.

As Declarações Francesa e Americana que são marcos tradicionais para os Direitos Humanos são resultados de processos liderados por burgueses proprietários ainda desprovidos de poder político, e consolidaram as teorias do contrato social em sua fundamentação. (BRAGATO, 2014, p. 209)

As ideias que estão no centro dessa gênese contemporânea dos Direitos Humanos, como a não discriminação e a dignidade, são dificilmente perceptíveis no legado europeu da Revolução Francesa que, além de invisibilizar as demandas das mulheres, tampouco questionou a escravização da população negra ou os massacres populacionais nas colônias impostas pela

\footnotetext{
${ }^{1}$ Ou seja, o direito natural do século XVIII funda um sistema positivado que se chamaria, num primeiro momento, direitos do homem e, mais tarde, Direitos Humanos. Assim, o racionalismo científico jurídico incorpora influências elitistas e androcêntricas que precisam ser diagnosticadas. (BRAGATO, 2014)
} 
Europa $^{2}$. (BRAGATO, 2014; FLORES, 2009)

Assim, uma compreensão decolonial ocupa lugar central nos objetivos do presente estudo, pois reflete criticamente o fenômeno dos Direitos Humanos, expandido a sua concepção para além do recorte moderno das doutrinas tradicionais. Este pensamento possibilita narrar a modernidade desde a sua outra face, evidenciando que a racionalidade moderna tem seu início antes mesmo dos movimentos pretensiosamente revolucionários.

O paradigma cartesiano e etnocêntrico dos Direitos Humanos (racionalismo ou idealismo) perde sua força quando os diversos olhares críticos sobre o direito questionam a tradição liberal da práxis jurídica. A crítica relaciona-se com o processo de desnaturalização das categorias, com a revelação de que o campo jurídico é uma arena de disputas, de conflito e de resultados. (WOLKMER, 2010)

Busca-se, então, uma interpretação relacional dos direitos em que fixá-los no “espaço onde nos movimentamos (ação), na pluralidade dos corpos (corporalidade) e na história exige uma nova metodologia que abranja esses conceitos em suas mútuas relações consigo mesmos e com os processos sociais em que se acham inseridos" (FLORES, 2009, p. 85-86). Não há conquista de direitos (resultados) sem redução das desigualdades sociais, sendo necessário ir além da mera normatividade e da concepção neutra e "a priori” dos Direitos Humanos.

Ninguém possui direitos antes de ter capacidades e condições adequadas para poder exercê-los. Pelo contrário, como produto da cultura, que ainda é racista, sexista e classista, o atual discurso, a internacionalização e a "ongnização" dos direitos (GALINDO, 2013) por vezes justifica ideologicamente diferentes formas de dominação, exploração e exclusão entre seres humanos, bem como a concentração de poder político e econômico.

As escolas críticas do direito pulsam em diversos locais, mas, sem deixar de referenciar as importantes contribuições da Escola de Frankfurt que, de modo geral, reaproximou as epistemologias jurídicas às realidades sociais, neste trabalho adota-se uma crítica atrelada, especialmente, aos estudos decoloniais ${ }^{3}$. Para transcender a colonialidade (a

\footnotetext{
2 Por exemplo, Flores (2009, p. 186) nos lembra que "Los condenados de la tierra", de Frantz Fanon, é um texto que fala mais sobre Direitos Humanos do que a miríade de reflexões acadêmicas sobre o tema. Para uma maior compreensão verificar: FANON, Frantz. Os condenados da terra. Rio de Janeiro: Civilização brasileira, 1968.

${ }^{3} \mathrm{O}$ programa da modernidade-colonialidade - mais conhecido através da noção de giro decolonial - começou como um tipo de grupo de estudos subalternos latino-americano, inspirado na proposta pioneira de colegas indianos (BALLESTRIN, 2013). O neologismo decolonial foi uma sugestão feita por Catherine Walsh, criado pelo Grupo Modernidade/Colonialidade. Sem o "s" demarcaria a diferença entre a proposta desse Grupo e "a ideia
} 
modernidade é um processo intrinsecamente vinculado à experiência colonial) no contexto da Abya Yala ${ }^{4}$, opta-se por um projeto pluralizado, de forma que pode haver tantas propostas de alter saberes e de ressignificados direitos na linguagem jurídica, quanto de epistemologias no mundo.

Essa perspectiva decolonial pode ser pensada como um campo capaz de resgatar os saberes subalternizados na linguagem oficializada dos Direitos Humanos, desoficializando-a e, assim, propiciando uma hermenêutica descolonizadora de novas práticas e epistemologias “outras". Como ensina Ballestrin (2013), o projeto decolonial, em suma, busca desaprender para reaprender. Além da crítica ao sistema capitalista vigente que acelera o processo de degradação do meio ambiente e acentua as desigualdades, é preciso recordar que não haveria uma economia capitalista mundial sem a existência das colônias americanas (QUIJANO; WALLERSTEIN, 1992).

O fenômeno da colonização imperial ou externa de povos não terminou com a extinção do colonialismo histórico-político nas Américas (século XIX), bem como na África e Ásia (século XX). A acumulação primitiva colonial foi um elemento indispensável na dinâmica interna e posterior continuidade do capitalismo e o fenômeno da colonialidade permanece em uma subjugação político-econômica e cultural dos países periféricos (QUIJANO, 2005).

A construção das hierarquias raciais, de gênero e também de modos de apropriação dos recursos naturais, pode ser vista como simultânea e contemporânea à constituição de uma divisão internacional do trabalho (também sexual, racial e de classe), marcada por relações assimétricas entre economias do centro e periféricas. Deve-se, portanto, enfrentar quatro colonialidades de forma articulada: do poder, do saber, do ser e da natureza (QUIJANO, 2005).

A depredação em larga escala da natureza é uma das fases da colonização e o extrativismo revela a colonialidade pois ainda é modelo para o desenvolvimento econômico. "Extrair, exportar e explorar" é um legado da lógica colonial que se reatualiza como

histórica de descolonização, via libertação nacional durante a Guerra Fria" (BALLESTRIN, 2013, p. 108). Além disso, cabe ressaltar a crítica de Rivera Cusicanqui (2010), que apontou a multiplicação de termos que abordam de maneira diferente a temática como modismos acadêmicos. Descolonizar o pensamento é não hierarquizar o olhar. Não se trata de ignorar os clássicos, mas de estabelecer uma relação crítica, e não privilegiá-los em detrimento de outros saberes comunitários que desafiam a lógica dada. Não se trata de apenas trocar categorias analíticas ou substituir o "recheio", mas ousar pensar de forma verdadeiramente diferente. Tais críticas devem ser objeto de reflexão e, ao longo do trabalho, tentar-se-á observar essas premissas.

${ }^{4} \mathrm{O}$ termo utilizado Abya Yala, na língua do povo Kuna, nação indígena que atualmente vive na região do Panamá, significa Terra Madura, Terra Viva ou Terra em Florescimento e é sinônimo de América Latina. (CURIEL, 2015) A retomada da denominação significa um ato de resistência à dominação dos invasores que subjugou a identidade dos povos originários. 
instrumento de necropolítica (MBEMBE, 2018), pois gera dor, fome, conflitos e mortes.

Há uma desagregação do território e do tecido social, pois os produtos dessas práticas extrativistas são exportados através de mão de obra barata em uma prática genocida contra o meio ambiente local e as populações vulneráveis afetadas, em uma nova forma de acumulação capitalista. As práticas de degradação ao meio ambiente hoje são financeirizadas ${ }^{5}$ e não há nenhuma relação equilibrada com o meio natural. Por conseguinte, há uma colonialidade na apropriação da natureza que se traduz na existência de formas hegemônicas de se explorar os recursos naturais, reduzindo-os a meras mercadorias, ao mesmo tempo em que evidencia o aniquilamento de modos subalternos de convívio com o meio ambiente.

Retomar a hermenêutica dos Direitos Humanos, repensando-os sob os motes decoloniais e, também, não patriarcais, é reconceituar o próprio direito ao meio ambiente saudável, fundado em uma cosmologia distinta (e pluralista, voltada à diversidade). O direito fundamental à terra vinculado ao direito à vida, e este ligado à coletividade; os direitos aos bens naturais essenciais concebidos não em uma relação de sujeição, mas positivamente simbiôntica; a garantia da biodiversidade e a preservação dos conhecimentos ancestrais (sociobiodiversidade). Toda essa construção foi erigida em uma evidente contraposição às monoculturas do saber e aos epistemicídios coloniais (DE SOUSA SANTOS; MENESES, 2009).

Apesar de as mudanças sociais também resultarem de processos políticos de combates no campo jurídico, elas são consequências, principalmente, de uma concentração de disputas desencadeadas pelos movimentos sociais, pela práxis social ${ }^{6}$, na compreensão de que os Direitos Humanos são processos, “ou seja, o resultado sempre provisório das lutas que os

\footnotetext{
${ }^{5}$ Não apenas por práticas claras como o "Mercado de Créditos de Carbono", mas, de modo geral, o sistema climático, árvores, oxigênio, bacias hidrográficas e toda a biodiversidade são "capitais naturais". Os perigos da financeirização da natureza não promovem simplesmente sua mercantilização, mas colocam o manejo dos bens naturais nas mãos dos mercados financeiros e do seu entorno especulativo. O próprio conceito de desenvolvimento sustentável, termo que surge em meados da década de 1970, é criado de forma concomitante ao processo de consolidação do sistema capitalista, mediante o reconhecimento da fragilidade dos ecossistemas. Misoczky e Böhm (2012) fazem uma reflexão crítica sobre a evolução do discurso do desenvolvimento sustentável (investida encoberta do capital sobre a natureza) e da economia verde (investida radical e aberta do capital sobre a natureza) relacionando-os a práticas similares e contínuas que permitem ao capital cooptar conceitos inicialmente radicais, de modo a incluí-los em sua lógica de acumulação. Da mesma forma, é possível analisar que, nessa lógica, tanto a natureza, quanto os corpos envolvidos nessa exploração, são mercantilizados devido à existência de um conflito vida-capital (PÉREZ, 2014), que explora e esgota ecossistemas e seres humanos, mas, com mais intensidade, as mulheres indígenas.

${ }^{6}$ Segundo Dussel, a práxis social, entendida em seu sentido fundamental, corresponde à estrutura total das ações sociais de uma época (1983, p. 24) e, neste contexto, faz-se necessária a qualquer análise e/ou teoria que se queira explicadora das relações sócio-políticas dentro de um contexto histórico.
} 
seres humanos colocam em prática para ter acesso aos bens necessários para a vida” (FLORES, 2009, p. 28).

Dessa maneira, é inegável a importância de se repensar o "humano" dentro do direito, que tradicionalmente foi erigido como uma herança perversa da colonização em processos diferenciais e desiguais, sustentados pela dicotomia fundante da colonial/modernidade: humanos e não humanos (LUGONES, 2014). Convoca-se, no próximo capítulo, a transversalidade das perspectivas de gênero e de raça nas articulações jurídicas, localizando os corpos que representam uma matriz não colonizante.

\section{OS FEMINISMOS ANDINOS E COMUNITÁRIOS LOCALIZADOS}

O aprofundamento e a inserção substantiva (e não de forma apenas adjetiva) no campo jurídico das práticas e das teorias decoloniais e não patriarcais que acontecem no exterior dos muros da academia, sempre referenciando e reconhecendo o protagonismo desses saberes, é uma estratégia a ser seguida na tarefa de descolonizar o direito ${ }^{7}$. Nesse contexto, interpretase os Direitos Humanos a partir das mulheres localizadas no Sul Global, especialmente desde o feminismo comunitário.

Esta propuesta ha sido elaborada desde el pensamiento y sentir de mujeres indigenas
que nos asumimos feministas comunitarias, en este caso las aymaras bolivianas de
Mujeres Creando Comunidad y las mujeres xinkas integrantes de la Asociación de
Mujeres indigenas de Sta. María en la montaña de Xalapán, Guatemala, para aportar
a la pluralidad de feminismos construidos en diferentes partes del mundo, con el fin
de ser parte del continuum de resistencia, transgresión y epistemología de las mujeres
en espacios y temporalidades, para la abolición del patriarcado originario ancestral
y occidental (CABNAL, 2010, p. 117).

O grupo Mujeres Creando Comunidad ${ }^{8}$ foi impulsionado por Julieta Paredes em 2001 e adota o "feminismo comunitário" como uma linha distinta, pautando uma convergência entre tendências feministas autônomas e os movimentos populares (CHAVES, 2020). A comunidade é lugar de identidade comum, de memória ancestral, em que não há direito

\footnotetext{
${ }^{7}$ Descolonizar o direito significa a realização de um giro decolonial no sistema jurídico e nas próprias estruturas estatais, tendo como base o passado e o presente das realidades vividas como dominação, exploração e marginalização, constituindo uma resposta social, política, ética e epistêmica enunciada desde o "outro" como um novo sujeito político (WALSH, 2006, p. 27).

${ }^{8}$ É resultado da cisão do grupo Mujeres Creando que é um coletivo fundado em 1993 e que se identifica e opera suas lutas através de uma linha mais autônoma do feminismo latino-americano (autonomia em relação aos homens, em relação aos partidos políticos, em relação ao Estado). (GALINDO, 2013)
} 
exclusivamente individual, mas deve ser interpretado sob sua dimensão coletiva.

Assim, a própria filosofia comunitária reflete uma compreensão integrativa dos Direitos Humanos, não segregacionista e orgânica, pois se "mete el cuerpo, jugándose en la práctica feminista comunitaria un proyecto de nación, y no sólo un trabajo intelectual" (GARGALLO, 2012, p. 152). O feminismo comunitário luta pela comunidade de comunidades e para que as relações sejam pautadas no comum (CHAVES, 2020). Por esse motivo, Ballestrin (2017) classifica-o como um feminismo subalterno?.

O grupo então intenta criar pontes ao aproximar-se dos povos bolivianos e propõe uma construção diária de uma prática e teoria nas/das ruas e uma exploração do poder transformador da criatividade. A sua força é voltada para o trabalho pedagógico com mulheres indígenas e da classe trabalhadora na Bolívia e em outras regiões da América Latina.

Por eso decimos que el feminismo, para el feminismocomunitario, es la lucha de
cualquier mujer: nosotras en Bolivia, Latinoamérica y el Caribe, Abya Yala, de las
europeas, las africanas, las asiáticas, etc., la lucha de todas. El punto de partida tiene
que ver con el cuerpo como experiencia histórica, material y politica; el cuerpo mujer
es la base histórica material de la que partimos. Se trata del cuerpo vivido, el cuerpo
comprendido politicamente desde la filogénesis de la humanidad, que tiene tres
cuerpos: mujer, hombre y personas intersexuales. Desde el devenir de nuestro cuerpo
mujer como humanidad y también el devenir individual como ser, ontológicamente
hablando, desde nuestra historia personal, desde la reflexión sobre el mundo. Mundo
al cual llegamos con estos cuerpos de mujer aqui y ahora, en este tiempo y en estos
territorios y por supuesto todo lo que nosotras queremos ser y hacer (PAREDES,
$2017, \mathrm{~s} / \mathrm{p})$.

Os feminismos andinos, populares e comunitários, em geral, vinculam a luta pela despatriarcalização de suas sociedades com a superação do capitalismo, do etnocentrismo e do antropocentrismo. A partir desse marco, redefinem a comunidade como lugar de pertença e confluência política e afetiva, e concebem a Pachamama como o lar que contém vida, que permite o encontro e a mobilização, pois para "el mundo andino todo elemento de la naturaleza DA y RECIBE para contribuir a un bien común, LA VIDA en armonía" em um "autosostenimiento económico" (CABNAL, 2010, p. 128), não como um sinônimo reducionista de fertilidade e reprodução a serviço do patriarcado (AGUINAGA et al, 2011).

O que é o patriarcado? Para nós, feministas comunitárias, patriarcado é o sistema de todas as violências, opressões e discriminações que vive a humanidade. Como eu disse, a humanidade para nós é um conjunto das mulheres, homens e pessoas intersexuais. O patriarcado é o sistema de todas as opressões sobre a humanidade e sobre a mãe / irmã natureza. Não oprime apenas a humanidade, mas também a natureza. Porém, o patriarcado é historicamente construído sobre o corpo das

\footnotetext{
${ }^{9} \mathrm{O}$ termo subalterno teria origem em Gramsci: "como classe ou grupo desagregado e episódico que tem uma tendência histórica a uma unificação sempre provisória pela obliteração das classes dominantes" (BALLESTRIN, 2013, p. 93)
} 
mulheres. É importante compreender que o patriarcado oprime também aos homens, não da mesma maneira, mas oprime também aos homens. E existem mulheres que por estarem inseridas no sistema patriarcal, são opressoras de mulheres e de homens. (CHAVES, 2020, p. 291-292)

Assim, ao convocar a luta por Direitos Humanos em interconexão à defesa da natureza, sem, necessariamente, afirmarem-se como ecofeministas ou ativistas, essas mulheres interligam o debate à problematização de classe e gênero a outras temáticas igualmente importantes como imperialismo, colonialismo e racismo. A partir dessa leitura complexa, abrem-se novas abordagens que são especialmente relevantes para a reformulação das relações entre o ser humano e a natureza.

Outro tópico de destaque das epistemologias comunitárias feministas latinoamericanas é a sua conceituação e aprofundamento na temática da ancestralidade como memória coletiva, como habilidade de preservar a si mesmo, neste mundo que é maior do que o indivíduo e, por consequência, de preservar a própria vida de forma que transcende o tempoespaço e se funde com o zelo perante a natureza.

Em especial, a cosmo-praxis andina (ARNOLD, 2017) compreende a ontologia relacional a partir da qual se assume outras formas de relacionamento mais simétricas entre os humanos, animais, plantas, em que tudo tem vida, seu tempo e seu lugar no Cosmos, e a humanidade faz parte da grande comunidade de inter-relações que fluem reciprocamente e de forma complementar.

$\mathrm{O}$ atual sistema capitalista e a revolução tecnológica, através de um molde individualista, maquínico ${ }^{10}$ e imediatista da subjetividade (GUATTARI; ROLNIK, 1986), opera em uma lógica que tende a destruir as memórias coletivas através do isolacionismo e da alienação em relação ao meio ambiente, características concentradas nos grandes centros urbanos e resultantes da "digitalização da vida".

Para as feministas comunitárias, esse processo também enfraquece a capacidade de resistir dos povos às violações de direitos, pois só existe resistência no sentimento de pertença a um corpo maior, na memória viva das histórias de quem lutou antes. Em comunidades onde as memórias coletivas estão presentes, reconstrói-se o sentido de identidade e pertencimento ao

\footnotetext{
${ }^{10}$ No cenário contemporâneo, a subjetividade é bem mais valiosa do que o petróleo (GUATTARI; ROLNIK, 1986, p. 26). Nossa subjetividade é de natureza maquínica, ou seja, "essencialmente fabricada, modelada, recebida, consumida" (GUATTARI; ROLNIK, 1986, p. 25). A produção de subjetividades em escala industrial é regida pela lógica de funcionamento capitalista em escala internacional. Há uma perigosa relação entre os processos de subjetivação e o modo de funcionamento do sistema capitalista, quando o segundo cada vez mais se entrelaça ao primeiro.
} 
terreno e às pessoas de sua rede de solidariedade, pois preservar e transmitir o conhecimento ancestral é "tecer a memória""11 (NAVARRO, 2015, p. 264).

A teorização sobre ancestralidade e memória coletiva está conectada à discussão sobre a temporalidade que reflete as lutas por direitos, a qual não é estática, nem linear, mas cíclica ${ }^{12}$, sendo necessária também a sua descolonização a fim de compreender os processos de avanços na conquista de direitos e, inclusive, os modos e as razões que operam seus retrocessos.

A própria divisão teórica dos Direitos Humanos em gerações está arraigada em um modelo pedagógico compartimentado, sendo obstáculo a compreensão integral da proteção do ser humano. A partir desses levantamentos, é possível identificar algumas pontes que podem ser criadas entre as práticas comunitárias de mulheres e a revolução ecocêntrica do direito.

\section{ECOLOGIZANDO AS CIÊNCIAS JURÍDICAS E OS DIREITOS HUMANOS A PARTIR DAS MULHERES COMUNITÁRIAS DO SUL GLOBAL}

Um dos marcos da reforma das epistemologias jurídicas no contexto da virada ecológica do direito é a superação da referência antropocêntrica das ciências humanas, enquanto a pauta de diversas teorias feministas é a superação do androcentrismo científico. A perspectiva antropocêntrica está intimamente conectada à androcêntrica, pois diversas mulheres demonstraram que o paradigma científico cartesiano que parte de uma observação unidirecional sujeito-objeto reflete esse sujeito como uma figura idealizada masculina e eurocentrada. Assim, transformar "el modelo androcéntrico de desarrollo, conquista y explotación destructivos implica tanto asumir una mirada empática sobre la Naturaleza como un análisis crítico de las relaciones de poder" (PULEO, 2002, p. 22).

Inseridas nessa matriz antropocêntrica-androcêntrica, as promessas desenvolvimentistas, mas sustentáveis, devem ser questionadas a partir de uma análise utilitarista desse discurso que beneficia pessoas localizadas. Conforme afirma Mies (1993), é um mito que todas as sociedades estão aptas a alcançar esse "desenvolvimento" à medida que seguem um processo de industrialização e informatização. O padrão de produtividade e consumo de sociedades ao Norte, por exemplo, pressupõe a externalização das demandas e dos custos, o que inviabiliza a extensão desse padrão para todas as partes do mundo.

\footnotetext{
${ }^{11}$ No Brasil, cabe ressaltar que as mulheres negras também são protagonistas nessa teorização com o lema: “nossos passos vêm de longe" (WERNECK, 2009).

12 Sobre a descolonização do tempo, ver Julieta Paredes (2017) e Rivera Cusicanqui (2010).
} 
Porém, enquanto os países do Sul acreditarem veemente nessa mentira, continuarão sustentando esse sistema que implica na exploração da força de trabalho e da natureza no âmbito interno. A "parceria” internacional é, na verdade, um modelo de coerção e violência, visto que ao sistema econômico dos países inferiorizados não restaria outra opção senão a de ceder às pressões do mercado externo.

Para Mbembe (2018) natureza ainda é aquele "todo selvagem" a ser convertido em algo civilizado por meio do processo neoliberal e colonizador. As mortes dos ecossistemas e da população que perpassam o caminho do progresso são justificadas como necessárias em defesa da produtividade. Há um cruzamento permanente da precariedade da vida que torna alguns corpos mais vulneráveis, ao que o autor ${ }^{13}$ descreveu como a "necropolítica": políticas de morte para o controle das populações (morte ou risco de morte como objetos de gestão).

$\mathrm{O}$ "direito de matar", na visão do teórico, estaria estreitamente relacionado às "relações de inimizade", elegendo de forma ficcional grupos inimigos, como aqueles que impossibilitariam esse "progresso" (MBEMBE, 2018), sendo que essas pessoas são selecionadas geralmente segundo grupos biológicos, apresentando o racismo como sua máxima expressão (indígenas, por exemplo, animalizados e historicamente destituídos de humanidade pela narrativa colonial $)^{14}$.

Dessa forma, é de fundamental importância delimitar que a ecologização dos Direitos Humanos deve ter como horizonte um movimento corporificado: deve-se afirmar e reafirmar a defesa do meio ambiente conectada à defesa dos direitos das populações comunitárias, indígenas, quilombolas, dentre outras, em todas as instâncias, populares e institucionais, em níveis nacionais e internacionais.

As reverberações atuais do giro ecocêntrico protagonizado pela hibridização das

\footnotetext{
13 Quando o funcionamento do Estado escancara a necropolítica como regime de governo das populações, passamos a descrever a desordem como "emergência", "conflito armado" ou "crise humanitária" (MBEMBE, 2018; AGAMBEN, 2015). Mbembe reafirma que hoje se mata mais em um curto prazo de tempo através de processos técnicos silenciosos (a burocracia, por exemplo, como uma maneira discreta de matar) e, até mesmo, algumas execuções nada discretas para satisfazer certo público, nutrindo uma ligação perversa entre justiça e vingança. (MBEMBE, 2018)

${ }^{14}$ A necropolítica relaciona-se com o conceito de "guerra contra as mulheres" cunhado por Segato (2016). A violência generalizada contra as mulheres e os feminicídios são fenômenos políticos que se apropriam e consomem os corpos femininos, dentro da lógica cis-heteropatriarcal do poder, do capital e de objetificação em massa. Essa repetição da cena violenta produz um efeito de normalização dessa "paisagem de crueldade" indispensável para esta "empresa predatória". (SEGATO, 2016) Analogicamente, observa-se um processo semelhante que opera sobre a depredação dos recursos naturais e a expropriação dos territórios, em uma necropolítica territorial e ambiental, que afeta certas mulheres de forma mais intensa, como as mulheres indígenas e campesinas, por exemplo.
} 
práxis e das teorias locais de povos oriundos do Sul na Teoria dos Direitos Humanos na América Latina já atingiram níveis interamericanos. Essa transição de paradigmas, ocorre inclusive nas jurisprudências convencionais.

Em uma análise dos casos julgados pela Corte IDH, por exemplo, identificaram-se 13 decisões ${ }^{15}$ relacionadas a questões ambientais que apresentam traços de ecologização de sua jurisprudência. Destes, 11 casos se relacionam a direitos de populações indígenas ou outras comunidades originárias. Apenas para exemplificar, no caso Povo Indígena Kichwa de Sarayaku c. Equador, a Corte reconheceu o caráter intergeracional da propriedade em uma concepção ecologizada desse direito, construída a partir da cosmovisão indígena (CAVEDONCAPDEVILLE, 2018).

As demandas demonstraram uma consequência natural da necessidade de adequar estes direitos em sua vertente clássica e, muitas vezes, etnocêntrica, à visão de mundo, à identidade cultural e à relação com a natureza dos povos autóctones da América Latina. É metodologicamente e eticamente indispensável reconhecer que essa episteme ecologizada advém das lutas comunitárias a fim de não reproduzir os apagamentos históricos sistemáticos do Outro ${ }^{16}$ (DUSSEL, 1994), com o intuito de não cometer os comuns epistemicídios da modernidade colonial (DE SOUSA SANTOS; MENESES, 2009).

Muitas vezes, a preocupação com a expansão econômica indefinida de um planeta é estereotipada como uma demanda de uma "elite preocupada com o aquecimento global". Nos meios intelectualizados, de fato, as metas do nascente movimento ecologista apontam para uma série de acontecimentos sociais e acadêmicos ${ }^{17}$ ocorridos por volta dos anos setenta. Nesse período surge o termo ecofeminismo, cunhado na Europa por "Françoise d'Eaubonne" (PULEO, 2019, p. 165).

\footnotetext{
${ }^{15}$ Comunidade Mayagna (Sumo) Awas Tigni c. Nicarágua (2001); Comunidade Yakye Axa do Povo Enxet-Lengua c. Paraguai (2005); Comunidade Sawhoyamaxa c. Paraguai (2006); Povo Saramaka c. Suriname (2007); Comunidade Xákmok Kásek c. Paraguai (2010); Povo Indígena Kichwa de Sarayaku c. Equador (2012); Comunidades afrodescendentes deslocadas da bacia do rio Cacarica (Operação Gênesis) c. Colômbia (2013); Povos indígenas Kuna de Madungandí e Emberá de Bayanos c. Panamá (2014); Povos Kalina e Lokono v. Suriname (2015); Comunidade Garifuna Triunfo de la Cruz c. Honduras (2015): Comunidade Garifuna de Punta Piedra c. Honduras (2015); Comunidades Indígenas Membros da Associação Lhaka Honhat c. Argentina (2020).

${ }^{16}$ Segundo Dussel, a modernidade nasce quando a Europa tem a possibilidade de confrontar-se com o "Outro" e controlá-lo, vencê-lo, violentá-lo; quando o europeu pode se identificar como um "ego" descobridor, colonizador da alteridade constitutiva desta modernidade. Neste sentido, o Outro não é descoberto como outro, mas encoberto como "não-europeu" (DUSSEL, 1994, p. 8), como figura abstrata.

17 "Dois dos estudos mais influentes que abordaram essas temáticas foram The Population Bomb (1968), livro de Paul Ehrlich, professor na Universidade de Standford, e o relatório Limits to Growth, de 1972, obra de uma equipe de investigação do Instituto Tecnológico de Massachusetts" (PULEO, 2019, p. 165).
} 
De acordo com Puleo (2002, p. 37-39), as teorias ecofeministas podem ser divididas em três tendências: a) Ecofeminismo clássico; b) Ecofeminismo espiritualista do Terceiro Mundo; e c) Ecofeminismo construtivista. Tem-se sublinhado as afinidades de todas as vertentes no que se refere a: a) vincular o domínio da natureza, de certa forma, à opressão das mulheres; b) propor o fim da destruição ecológica e da subordinação feminina em um esquema de emancipação conjunta; c) unir a crítica ao forte antropocentrismo com a crítica ao viés masculino da cultura; d) convidar a uma redefinição ético-política dos conceitos de natureza e ser humano.

Assim, em busca de uma compreensão crítica, o pensamento ecofeminista proporciona uma tomada de consciência da falta de valorização das práticas do cuidado com a natureza e com os seres humanos. Longe de estereotipar o feminino neste trabalho, defende-se uma linha construtivista que incorpora características da segunda tendência em que a opressão das mulheres e a exploração intensiva da natureza possuem origem no sistema patriarcal, colonial e racista, que foi acentuado no sistema capitalista.

Cabe fazer referência ao protótipo ecológico referenciado na Pachamama para o movimento Mujeres Creando Comunidad. Em 2010, o grupo, durante a realização da Conferência dos Povos sobre Mudança Climática em Cochabamba (Bolívia), realizou o seguinte pronunciamento ${ }^{18}$ :

Entendemos a la Pachamama, a la Mapu, como un todo que va másallá de la naturaleza visible, que va másallá de los planetas, que contiene a la vida, las relaciones establecidas entre los seres con vida, sus energías, sus necesidades y sus deseos. Denunciamos que la comprensión de Pachamama como sinónimo de Madre Tierra es reduccionista y machista, que hace referencia solamente a la fertilidad para tener a las mujeres y a la Pachamama a su arbitrio patriarcal. "Madre Tierra", es un concepto utilizado hace varios años y que se intenta consolidar en esta Conferencia de los pueblos sobre Cambio Climático con la intención de reducir a la Pachamama - así como nos reducen a las mujeres-a su función de útero productor y reproductor al servicio del patriarcado. (Mujeres Creando Comunidad, 2010, s/p).

Em relação à colonialidade do poder sobre os conceitos Pachamama e Buen Vivir ${ }^{19}$, há certas categorias políticas que estão em constante dupla disputa: política e epistêmica

18 Mujeres Creando Comunidad.

Disponível em: $<$ http://mujerescreandocomunidad.blogspot.com.br/2010/04/pronunciamiento-del-feminismo.html $>$. Acesso em 15 de jul. 2020.

19 Também conhecido por suma qamaña ou Sumak Kawsay. "Sumak es una palabra enunciada en idioma quichua ecuatoriano y expresa el pensamiento de una vida no mejor, ni mejor que la de otros, ni en continuo desvivir por mejorarla, sino simplemente buena en integralidad. Es la plenitud, lo sublime, excelente, magnifico, hermoso(a), superior. La segunda palabra Kawsay proviene del idioma aymara boliviano y en su interpretación introduce el elemento comunitario, por lo que se podría traducir como 'buen convivir': buena para todos en suficiente armonía interna. Es la vida, es el ser estando. Es dinámico, cambiante. No es pasivo”. (CABNAL, 2010, 123-124) 
(AGUINA, 2012). Em especial, os feminismos andinos, ao exporem suas críticas aos processos de personificação da Pachamama, rejeitando os vieses essencialistas, bem como as orientações propagandistas governamentais e "onusianas" do termo, estão realizando os procedimentos de reinterpretação e disseminação de ideias, entrelaçadas a partir das relações de poder existentes.

Durante a Cúpula dos Povos em 2012, evento paralelo à Conferência das Nações Unidas sobre Desenvolvimento Sustentável $\left(\right.$ Rio $\left.+20^{20}\right)$, se veiculou a noção de Pachamama traduzida como Mãe Terra ou Mother Earth. A variante desses documentos é a relação feita entre Mãe Terra e a noção de Buen Vivir, como se atesta na Declaração Universal dos Direitos da Mãe Terra, bem como na Lei Boliviana n. $300^{21}$.

De certa forma, assim como o Equador, o Constitucionalismo Plurinacional Boliviano desde 2009 é um dos exemplos vanguardistas na incorporação de uma cosmogonia ancestral integrativa com a natureza em seu texto. Porém, o fenômeno do colonialismo interno (CUSICANQUI, 2010; PAREDES, 2017) e/ou da colonialidade do poder (QUIJANO, 2005) estabelece um empecilho na concretização das premissas do Buen Vivir, que levou parte do indianismo a criticar atitudes do ex-presidente Evo Morales que contribuiria para preservar o imperialismo e o neoliberalismo no país, ocasionando a exploração desregrada da natureza.

A Bolívia, então, em certo nível prático, continuaria reproduzindo um tipo particular de racionalidade econômica-instrumental, a qual se apresenta como a razão por excelência no mundo global. Contraditoriamente, essa racionalidade moderna se opõe a uma racionalidade ambiental dos povos indígenas e das comunidades camponesas (QUIJANO, 2005). O feminismo comunitário boliviano, ao tentar realizar um diálogo e convergência entre tendências feministas autônomas e os movimentos populares, aponta essas contradições.

Assim, um resgate substantivo da figura da Pachamama pelo feminismo comunitário fundamenta a luta, por exemplo, de mulheres campesinas e/ou indígenas pelos seus direitos ao uso da terra/territórios, e reflete uma possibilidade prática do conceito em que a utopia dessa construção se revela real.

$\mathrm{Na}$ América Latina, uma filosofia espiritual integrativa do humano-cosmos-

\footnotetext{
${ }^{20}$ Disponível em: <http://riomais20sc.ufsc.br/files/2012/07/O-Futuro-que-queremos.pdfacesso $>$. Acesso em: 15 de jul. 2020.

${ }^{21}$ Denominada de Ley Marco de la Madre Tierra y Desarrollo Integral Para Vivir Bien, institucionalizada em $2012 . \quad$ Disponível em: $<$ http://www.harmonywithnatureun.org/content/documents/157Bolivia\%20Ley\%20300.pdf $>$. Acesso em: 15 de jul. 2020.
} 
natureza já funcionou como um movimento de união contra o colonialismo. Iniciado no Peru, o primeiro ataque em grande escala contra as antigas religiões pela Europa ocorreu em 1560, coincidindo com o surgimento do movimento Taki Onqoy, um movimento milenarista que argumentava contra o colaboracionismo com os espanhóis para pôr fim à colonização. (FEDERICI, 2017)

Os e as Takionqos atribuíam a derrota sofrida pela colonização de seus povos ao abandono dos deuses locais e incitavam as pessoas a recusarem o pagamento de tributos e o trabalho forçado imposto pelos espanhóis, e também a abandonarem o uso de elementos da cultura espanhola. A ameaça formulada pelos povos autóctones convocava uma unificação panandina dos huacas (deuses locais), marcando o começo de um novo senso da identidade latino-americana capaz de superar as divisões internas. Portanto, foi a primeira vez que o povo dos Andes enxergou-se em unidade, e o movimento expandiu-se amplamente do Peru à Bolívia. (FEDERICI, 2017)

Não é por acaso que as mulheres tiveram maior presença no movimento Taki Onqoy, pois foram elas que se destacaram na defesa do antigo modo de existência e que de forma mais veemente se opuseram à nova estrutura de poder, provavelmente devido ao fato de serem também as mais afetadas.

\begin{abstract}
Por todos esses motivos, as mulheres se converteram nas principais inimigas do domínio colonial, negando-se a ir a missa, a batizar seus filhos ou a qualquer tipo de cooperação com as autoridades coloniais, organizaram suas comunidades e, frente à traição de muitos chefes locais cooptados pela estrutura colonial, se converteram em sacerdotisas, líderes e guardiãs das huacas, assumindo tarefas que nunca antes haviam exercido. Isto explica por que as mulheres constituíram a coluna vertebral do movimento Taki Onqoy. (FEDERICI, 2017, p. 402)
\end{abstract}

Esse processo demonstra a cooptação e a junção dos patriarcados ancestral e colonial, formando, segundo Paredes (2017), um entronque patriarcal. Ao longo da história, ao ser aproximada da natureza pelo homem, a mulher passou a ser um espaço de invasão, dominação, exploração e controle. Em outras palavras, existe um fundamento antropocêntrico nas formas de dominação e essa operação que desqualifica e submete as mulheres ao campo da natureza é a mesma que submete a vida na terra. Nesse sentido, o popular grafite do grupo Mujeres Creando denuncia: "Ni la tierra ni las mujeres somos territorio de conquista".

Assim como houve insurgência no início do colonialismo pelas mulheres, há também na contemporaneidade. É necessário retomar o conceito corpo-territórrio e seu significado histórico a partir das quais se pode desconstruir e reconstruir a vida contra a política de hierarquia e morte, utilizando esse conceito ressignificado como um elemento importante para a ecologização dos Direitos 
Humanos. Analisar a colonialidade como a opressão histórica do corpo-território requer a problematização de raça, etnia, classe e gênero, além de desafiar os discursos hegemônicos ocidentais (CURIEL, 2015). A 'identidad étnica se finca en el cuerpo-tierra como el lugar de enunciación para la construcción del feminismo comunitario"' (GARGALLO, 2012, p. 114).

Nas relações sociedade-natureza, a terra é pensada como território, como base para a reprodução sociocultural da vida e onde se tecem os laços comunitários. Falar do corpoterritório permite compreender as raízes da dominação masculina e sua instrumentalização a favor do capitalismo e do patriarcado, através da exploração dos corpos das mulheres obrigadas a funcionar como meio de reprodução e da acumulação de trabalho e riqueza (FEDERICI, 2017), pois "Violentan nuestros derechos, cuando deciden sobre nuestros cuerpos de mujeres, por nuestra sexualidad y por nuestra tierra" (GARGALLO, 2012, p.152).

Nesse corpo indígena, também há uma sexualização da raça e uma racialização do sexo (LUGONES, 2014) a partir da multiplicidade de origens e condições sociais das mulheres de cada região. Assim, falar do corpo como território abre espaço para recontar uma história própria e implica na recuperação consciente do território dos corpos psíquicos e físicos, pessoais e coletivos, como ato político emancipatório (CABNAL, 2010).

Conectada a esse conceito, a divisão sexual do trabalho funciona como uma base da dupla opressão mulher-natureza, assim como é necessário desfazer a classificação das atividades humanas como "produtivas e reprodutivas". Os estudos sobre uma economia feminista e solidária sinalizam essa divisão, pela qual as mulheres são colocadas em situação de desvantagem e dependência, limitando seu acesso a direitos fundamentais e delegando-lhes, ainda, a carga de trabalho de cuidado tanto das pessoas, mas também dos ecossistemas e da defesa do território (NOBRE, 2008).

Tais premissas advindas do saber comunitário demonstram a urgência do debate sobre a interação humana equilibrada com o meio ambiente, sobre a não hierarquização e não exploração laboral, frisando-se a necessidade de se pensar e praticar a justiça social aliada à tutela da natureza. Essas críticas estão também conectadas à divisão de classes, racial e geopolítica do trabalho e vão ao encontro da Ecologia Política ${ }^{22}$, que entende por injusto o

\footnotetext{
${ }^{22}$ Muitas das abordagens sobre a ecologia política se estabeleceram dentro dos padrões epistemológicos de uma modernidade hegemônica. O discurso produzido a partir de Estocolmo-1972, repetido na Rio-92 e que continua nos dias atuais, trouxe o importante dialogo a respeito dos "modelos econômicos alternativos" e novas formas de "participação" da sociedade nos debates institucionais, porém, não questionam os aspectos profundos do sistema econômico vigente em que "a produção capitalista só desenvolve a técnica e a combinação do processo social na medida em que solapa os mananciais de toda a riqueza: a terra e o trabalhador" (MARX, 2004, p. 574). O
} 
acesso desigual (entre grupos de pessoas e/ou entre países) aos bens naturais. Outrossim, o cuidado com a vida aqui é desenhado como labor que deve estar no centro da organização social e ser assumido coletivamente.

Um segundo ponto crucial de destaque na práxis social comunitária é a defesa do antidualismo e a rejeição das divisões maniqueístas através de uma reinterpretação da dualidade original aymara Chacha-Warmi (literalmente, o Homem-Mulher). É necessário aprofundar o uso simplista de dicotomias hierárquicas e da lógica categorial, a qual é central para o pensamento capitalista e colonial moderno sobre raça, gênero e sexualidade (LUGONES, 2014, p. 935).

La dualidad no quiere decir nada, la complementariedad no quiere decir nada. Nosotras estamos manejando el concepto de reciprocidad, porque la reciprocidad si está hablando de dos iguales que reciprocamente se van a relacionar. No hablamos del ChachaWarmi sino de Warmi-Chacha y sí tomamos en consideración a toda la gama de personas intersexuales. (GARGALLO, 2012, p. 182)

Assim, enxerga-se o feminismo comunitário como um movimento que busca um novo mecanismo de legitimação dos Direitos Humanos, incluindo de forma autônoma o meio ambiente em sua valorização intrínseca. A lógica do agronegócio descomprometida com a segurança e soberania alimentar, os impactos antrópicos sobre a natureza de forma acumulativa e especulativa e a exploração e violência sobre corpos humanos são demandas urgentes que demonstram a crise do modelo tradicional dos Direitos Humanos que atualmente não se relaciona reciprocamente com a tutela da natureza de forma efetiva.

Essas mulheres comunitárias então refundam os projetos sócio-políticos e ecologizam os Direitos Humanos, pois lançam um olhar cosmovisional, não especista e integrado em um giro ecocêntrico quando "las reflexiones expuestas por las feministas comunitarias y otras feministas radicales, confrontaron las ideas de desarrollo, de consumo y de financiamientos porque las acciones comunitarias tienen rostros, nutren a quienes las ponen en marcha" (GARGALLO, 2012, p. 186). Para ilustrar essa mecânica, o exemplo boliviano constitui-se em um profícuo laboratório. Nos últimos anos, a Bolívia iniciou uma intensa investida no debate mundial sobre as mudanças climáticas vinculada à cosmovisão indígena (SVAMPA, 2010).

movimento ecológico é multifacetado e, sem olvidar as contribuições de Marx, adota-se o paradigma da Economia Política Feminista (EPF) que questiona as bases epistemológicas que constroem as relações da humanidade com o meio ambiente. Para tanto, são considerados aspectos do ecofeminismo, economia ecológica, economia feminista, feminismo socialista e feminismo pós-estruturalista. (ROCHELEAU et al, 2004). 
Ocorre que o modelo de desenvolvimento boliviano apresenta uma tensão padronizada: ao mesmo tempo em que a filosofia do Buen Vivir não pode ser equiparada com as políticas desenvolvimentistas clássicas, observa-se um grande salto industrial boliviano, mas também depredatório (SVAMPA, 2010). O discurso eco-pachamámico seria preponderantemente "de exportação", pois, segundo a autora, para o consumo interno predominaria uma retórica mais vinculada ao imaginário desenvolvimentista, com um Estado redistributivo forte e populista, de modelo essencialmente extrativista (que resultaram no exponencial crescimento do PIB no país na gestão Morales $^{23}$ ).

O "pachamamismo" gerou, ao mesmo tempo, uma ideia clara da crise do capitalismo como uma crise civilizatória tout court da modernidade ocidental, sem a forca de contra impactar os modelos de acumulação e suas consequências politicas. As mulheres indígenas e comunitárias desmascararam esse "progressismo", por exemplo, liderando marchas em 2011 e 2012 contra a construção de uma rodovia que atravessaria a Terra Indígena e o Parque Nacional Isiboro Sécure (TIPNIS), providenciando a infraestrutura de apoio necessária para as marchas (VIERREIRA, 2012 apud FEDERICI, 2020, p.3). Este caso se estende até os dias atuais e a Comissão Interamericana de Direitos Humanos (CIDH) aprovou o informe n. 113/20 neste ano, admitindo a petição apresentada por 64 comunidades indígenas que denunciaram o Estado Boliviano nesse caso ${ }^{24}$.

Como foi demonstrado, a resistência das mulheres à exploração econômicoecológica foi uma constante na história da América Latina. Na contemporaneidade elas permanecem na linha de frente contra as corporações transnacionais de mineração e do agronegócio que invadem áreas rurais e envenenam o meio ambiente (MEJÍA, 2016, p. 7, apud FEDERICI, 2020, p.3), e, na região amazônica, lideram a luta em defesa da água, como declarou a líder quíchua Patricia Guallinga de Sarayaku (GUALLINGA, 2014, p.48-50, apud FEDERICI, 2020, p.3).

Uma característica dos novos movimentos das mulheres comunitárias é o processo de radicalização política que eles refletem, pois seu ativismo não apenas protege as vidas de suas comunidades contra as atividades das companhias transnacionais e luta pela soberania

\footnotetext{
${ }^{23}$ Outra posição de Evo muito criticada pelo grupo teria sido sua passividade diante do recente incêndio da Chiquitania. No segundo semestre de 2019, uma série de incêndios que ocorreram nas regiões tropicais do Bosque Chiquitano (a "amazônia boliviana") afetou populações nos departamentos bolivianos de Santa Cruz e de Beni.

${ }^{24}$ Ver petição original em:<http://www.oas.org/es/cidh/decisiones/2020/boad211-12es.pdf >. Acesso em: 23 set. 2020.
} 
alimentar ou contra a engenharia genética de sementes, mas também busca transformar o atual modelo de desenvolvimento econômico em outro que respeite os seres humanos e a terra. Elas consideram que os problemas enfrentados não provêm apenas de políticas ou de empresas específicas, mas estão enraizados na lógica mercenária da acumulação de capital, a qual, atualmente, com a promoção de uma "economia verde", torna o meio ambiente um novo recurso para a especulação e o lucro. (FEDERICI; VALIO, 2020, p. 4)

Nesse quadro, falar hoje em apenas um simples reconhecimento da "autonomia" dos povos e de seus direitos torna-se uma estratégia insuficiente frente à materialidade do genocídio e da depredação ambiental. Revela-se, portanto, limites à soberania garantidas através do próprio Novo Constitucionalismo Latino Americano. É preciso criar novos preceitos para compreender os processos atuais, formar um novo vocabulário para dar conta de uma efetiva ecologização dos direitos. Essa nova racionalidade ambiental decolonial e feminista visa oxigenar o campo monocromático dos Direitos Humanos.

Igualmente, a crítica à dominação abarca não apenas as relações de dominação de classe analisadas por Marx (2013), mas também aquelas de dominação de gênero e de dominação da natureza. A crítica política abarca uma multiplicidade de conjuntos de atores e de vetores de luta: não apenas lutas de classe, mas também lutas sobre limites das separações entre sociedade, organização política, natureza e economia (FRASER, 2015).

O neoliberalismo, em sua prima face de autoexpansão desenfreada (FRASER, 2015), parece ter como único limite de crescimento os próprios recursos dos quais perversamente se alimenta: humanos e naturais (recursos estes que nem deveriam ser inteligíveis em separado). Os maiores freios desses processos autodestrutivos estão localizados em conhecimentos e práticas que esse mesmo sistema deslegitimou, hierarquizou, violentou, explorou e expropriou. Traça-se, a partir das trajetórias do feminismo comunitário, uma rota de fuga ao fatalismo social e natural.

Assim, o "feminismo comunitário" pode nos ensinar que o conceito de comum expressa uma direção específica de espaço, tempo, vida e corpo humano e tece possibilidades ao processo de virada ecológica nos Direitos Humanos: a reprodução e o cuidado relativo à vida material, a reapropriação da riqueza produzida coletivamente e o desenvolvimento de uma efetiva soberania/autonomia dos povos. 


\section{CONSIDERAÇÕES FINAIS}

Analisou-se de que forma a teoria e a práxis feminista comunitária latino-americana poderia propor novos critérios epistemológicos capazes de promover a ecologização dos Direitos Humanos e, também, a descolonização do Direito. Desenhou-se a historização colonial e linear dos Direitos Humanos e pontuou-se pela sua superação através de um marco latinoamericano comunitário decolonial e não cis-heteropatriarcal através de epistemologias dos povos originários que se encontram dentro e fora dos territórios acadêmicos.

O marco feminista comunitário pode ser considerado como um propulsor do movimento de virada ecológica nas ciências jurídicas e nos seus limites epistemológicos atuais. Percorrese o caminho da ecologização dos Direitos Humanos como um movimento corporificado nas lutas de povos originários, encontrando possibilidades para uma emancipação da teoria jurídica e uma hermenêutica expansiva do meio ambiente e do humano no direito.

Localizaram-se, no presente artigo, os feminismos comunitários latino-americanos e as suas propostas ecológicas cosmovisionárias e ecofeministas. A partir das condições concretas de mobilização por uma visão integrativa que promova o valor intrínseco da natureza, expostas pelo feminismo comunitário, demonstraram-se, por exemplo, os avanços e retrocessos no exemplo Boliviano e as representações sobre a ciclicidade das conquistas em direitos.

Portanto, o paradigma da modernidade e sua intrínseca historização colonial e linear dos Direitos Humanos necessita ser dialeticamente transposta para possibilitar que os Direitos Humanos reflitam a realidade de países latino-americanos e permitam a satisfação das necessidades concretas dos povos originários da América Latina. Neste sentido, o movimento da virada ecológica nas ciências jurídicas deve estar refletido na teoria dos Direitos Humanos e encontrar suportes decoloniais e não patriarcais produzidos a partir de um lócus de saberes originários do Sul Global advindos, especialmente, da práxis social comunitária e feminista.

Por fim, verificou-se que, neste recorte, as práticas e as teorias produzidas por mulheres comunitárias propõe novos critérios epistemológicos capazes de promover a ecologização dos Direitos Humanos e, também, a descolonização da ciência jurídica como um todo. Essas epistemologias possibilitam condições concretas de mobilização e zelo para com os direitos fundamentais e com o meio ambiente equilibrado, estruturadas em uma cosmovisão integrativa que promove o valor intrínseco da natureza. 


\section{REFERÊNCIAS}

AGAMBEN, Giorgio. Estado de exceção. Homo Sacer II, I. São Paulo: Boitempo, 2015.

AGUINAGA, Margarita; LANG, Miriam; MOKRANI, Dunia; SANTILLANA, Alejandra. Pensar desde el Feminismo: críticas y alternativas al Desarrollo. In: LANG, Miriam; MOKRANI, Dunia. Mas allá del Desarrollo. Grupo permanente de trabajo sobre alternativas al Desarrollo. Quito: Universidad Central del Ecuador, p. 55-82, 2011.

ARNOLD, Denise Y. Hacia una antropología de la vida en los Andes. Resignificaciones, interpretaciones y propuestas en la cosmo-praxis. In: MENDOZA, Heydi Tatiana Galarza. El desarrollo y lo sagrado en los Andes. LaPaz: ISEAT, 2017.

BALLESTRIN, Luciana Maria de A. América Latina e o giro decolonial. Revista Brasileira de Ciência Política, Brasília, n. 11, p. 89-117, mai-ago, 2013. Disponível em:

$<$ http://www.scielo.br/pdf/rbcpol/n11/04.pdf >. Acesso em: 21 maio. 2019.

. Feminismos Subalternos. Revista Estudos Feministas, v. 25, n. 3, Florianópolis, set-dez, 2017.

BRAGATO, Fernanda F. Para além do discurso eurocêntrico dos direitos humanos: contribuições da descolonialidade. Revista Novos Estudos Jurídicos - Eletrônica, v. 19, n. 1, p. 201-230, jan-abr. 2014.

BOLÍVIA. Constitución Política del Estado. Promulgada em 7 de fevereiro de 2009.

Disponível em:

$<$ http://revistaseletronicas.pucrs.br/ojs/index.php/faced/article/view/12319/8741>. Acesso em: 23 fev. 2020.

DE SOUSA SANTOS, Boaventura; MENESES, Maria Paula (Org.). Epistemologias do Sul. Coimbra: Almedina, 2009.

DUSSEL, Enrique. Práxis latinoamericana y filosofia de la liberación. Bogotá: Editora Nova América. 1983.

1492 El encubrimiento del Otro: hacia el orígen del mito de la modernidad. La Paz: Plural Editores, 1994.

CAVEDON-CAPDEVILLE, Fernanda de Salles. Jurisprudência ecologizada nas cortes de direitos humanos: contribuições para a ecologização dos direitos humanos. In: LEITE, José Rubens Morato. A ecologização do direito ambiental vigente. Rio de Janeiro: Lumen Juris, 2018.

CABNAL, Lorena. Acercamiento a la construcción de la propuesta de pensamiento epistémico de las mujeres indígenas feministas comunitarias de Abya Yala. In: Momento de paro. Tiempo de rebelión. Miradas feministas para reinventar la lucha. Minervas Ediciones, 2010.

CHAVES, Kena Azevedo. 'Hacia la 
Comunidad, Siempre', os Caminhos do Feminismo Comunitário: Entrevista com Julieta

Paredes. Revista Latino Americana de Geografia e Gênero, v. 11, n. 1, p. 286 - 298, 2020.

CURIEL, Ochy. La descolonización desde una propuesta feminista crítica. In:

Descolonización y despatriarcalización de y desde los feminismos de Abya Yala. España: Asociación para la Cooperación con el Sur, p. 27-50, 2015.

FEDERICI, Silvia. O Calibã e a Bruxa: mulheres, corpo e acumulação primitiva. Tradução: Coletivo Sycorax. SP: Elefante, 2017.

FEDERICI, Silvia; VALIO, Luciana Benetti Marques. Na luta para mudar o mundo: mulheres, reprodução e resistência na América Latina. Revista Estudos Feministas, Florianópolis, v. 28, n. 2, 2020. Disponível em:

$<$ http://www.scielo.br/scielo.php?script=sci_arttext\&pid=S0104-

026X2020000200200\&lng=en\&nrm=iso >. Accesso em 23 set. 2020.

FLORES, Joaquin. H. A (re)invenção dos direitos humanos. Traduzido por GARCIA, C. R. D. et al. Florianópolis: Fundação Boiteux, 2009.

FRASER, Nancy. Por trás do laboratório secreto de Marx. Direito \& Práxis, v. 6, n. 10, p. 704-728, 2015.

GALINDO, María. No se pude descolonizar sin despatriarcalizar: Teoría y propuesta de la despatriarcalización. La Paz: Editora Mujeres Creando, 2013.

GARGALlO, Francesca. Feminismos desde Abya Yala. Ideas y proposiciones de las mujeres de 607 pueblos en nuestra América. Bogotá: Ediciones desde abajo, 2010.

GUATTARI, Félix; ROLNIK, Suely. Micropolítica: cartografias do desejo. Rio de Janeiro: Vozes, 1986.

HARDING, Sandra. Existe um método feminista? In: Eli Bartra (Org.), Debates em torno a uma "metodologia feminista". México, D.F: UNAM, p. 9-34, 1998.

LAKATOS, Eva Maria; MARCONI, Marina de Andrade. Fundamentos de Metodologia Científica. $3^{\text {a }}$ ed. São Paulo: Atlas, 1993

LUGONES, María. Rumo a um feminismo descolonial. Revista Estudos Feministas, Florianópolis, v. 22, n. 3, set-dez. 2014. Disponível em:

$<$ https://periodicos.ufsc.br/index.php/ref/article/view/36755>. Acesso em: 21 jun. 2019.

MBEMBE, Achille. Necropolítica. 3. ed. São Paulo: n. 1 edições, 2018.

MARX, Karl. O Capital: crítica da Economia Política. Livro 1. São Paulo: Boitempo, 2013.

MIES, Maria. O mito do desenvolvimento catching-up. In: MIES, M; SHIVA, V.

Ecofeminismo. Lisboa: Instituto Piaget, p.77-94, 1993.

MISOCZKY, Maria Ceci; BÖHM, 
Steffen. Do desenvolvimento sustentável à economia verde: a constante e acelerada investida do capital sobre a natureza. Cad. EBAPE-BR-FGV, v. 10, n. 3, artigo 5, Rio de Janeiro, p. 546-568, set. 2012.

NAVARRO, Mina Lorena. Luchas por lo común: Antagonismo social contra el despojo capitalista de los bienes naturales em Mexico. Puebla: Bajo Tierra Ediciónes, 2015.

NOBRE, M. Economía solidaria y economía feminista: Elementos para una agenda. In: NOBRE, M. et al. Las mujeres en la construcción de la economía solidaria y la agroecología. Sao Paulo: Ediciones Empreviva Organização Feminista, p. 13-14, 2015.

QUIJANO, Anibal. Colonialidad del poder, eurocentrismo y América Latina. Buenos Aires: CLACSO, 2005. Disponível em: $<$ http://bibliotecária-arquivista/clacso/sursur/20100624103322/12_Quijano.pdf>. Acesso em: 10 jun. 2020.

; WALLERSTEIN, Immanuel. Americanity as a concept or the Americas in the modern world-system. International Social Science Journal, Paris, n. 134, nov. 1992.

PAREDES, Julieta. El feminismo comunitario: la creación de un pensamiento próprio. Corpus, v. 7, n. 1, 2017. Disponível em:

$<$ http://journals.openedition.org/corpusarchivos/1835>. Acesso em: 19 jun. 2019.

PATEMAN, Carole. O Contrato sexual. Rio de Janeiro: Paz e Terra, 1993.

PÉREZ, O. Subversión feminista de la economía. Sobre el conflicto capital-vida. Madrid: Traficantes de Sueños, 2014.

PETIT, Cristina M. La dicotomia público/privado en el pensamiento político ilustrado y liberal. In: Dialética feminista de la Ilustración. Barcelona: Anthropos, p. 29-104, 1994.

PULEO, Alícia H. Feminismo y Ecología. El Ecologista, n. 31. Espanha, 2002.

Perspectivas ecofeministas da ciência e do conhecimento: a crítica ao viés andro-antropocêntrico. Em Construção: arquivos de epistemologia histórica e estudos de ciências. Rio de Janeiro: PPGFIL-UERJ, n. 5, p. 163 - 173, 2019.

RIVERA CUSICANQUI, Silvia. Ch'ixinakax utxiwa: una reflexión sobre prácticas y discursos descolonizadores. Buenos Aires: Tinta Limón, 2010.

ROCHELEAU, Dianne; THOMAS-SLAYTER, Barbara; WANGARI, Esther. Feminist Political Ecology: global issues and local experiences. New York, USA: Routledge, 2004.

SEGATO, Rita. L. La guerra contra las mujeres. Madrid: Traficantes de Sueños, 2016.

SVAMPA, Maristella. El laboratorio boliviano. In: SVAMPA, Maristella; STEFANONI, Pablo; FORNILLO, Bruno. Debatir Bolivia. Buenos Aires: Taurus, 2010.

WALSH, Catherine. Interculturalidad, descolonización del Estado y del conocimiento. Buenos Aires: Del Signo. 2006. 
WERNECK, Jurema. Nossos passos vêm de longe! Movimentos de mulheres negras e estratégias políticas contra o sexismo e o racismo. Genève: Graduate Institute Publications, 2009.

WOLKMER, Antonio Carlos. Introdução ao pensamento jurídico crítico. 6a. ed. São Paulo: Saraiva, 2010.

Data de recebimento: 18.12 .2021

Data de aprovação: 04.03.2021 